\title{
High-definition micropatterning method for hard, stiff and brittle polymers
}

Citation for published version (APA):

Zhao, Y., Truckenmuller, R., Levers, M., Hua, W-S., de Boer, J., \& Papenburg, B. (2017). High-definition micropatterning method for hard, stiff and brittle polymers. Materials Science \& Engineering C-Materials for Biological Applications, 71, 558-564. https://doi.org/10.1016/j.msec.2016.11.004

Document status and date:

Published: 01/02/2017

DOI:

10.1016/j.msec.2016.11.004

Document Version:

Publisher's PDF, also known as Version of record

Document license:

Taverne

Please check the document version of this publication:

- A submitted manuscript is the version of the article upon submission and before peer-review. There can be important differences between the submitted version and the official published version of record.

People interested in the research are advised to contact the author for the final version of the publication, or visit the DOI to the publisher's website.

- The final author version and the galley proof are versions of the publication after peer review.

- The final published version features the final layout of the paper including the volume, issue and page numbers.

Link to publication

\footnotetext{
General rights rights.

- You may freely distribute the URL identifying the publication in the public portal. please follow below link for the End User Agreement:

www.umlib.nl/taverne-license

Take down policy

If you believe that this document breaches copyright please contact us at:

repository@maastrichtuniversity.nl

providing details and we will investigate your claim.
}

Copyright and moral rights for the publications made accessible in the public portal are retained by the authors and/or other copyright owners and it is a condition of accessing publications that users recognise and abide by the legal requirements associated with these

- Users may download and print one copy of any publication from the public portal for the purpose of private study or research.

- You may not further distribute the material or use it for any profit-making activity or commercial gain

If the publication is distributed under the terms of Article $25 \mathrm{fa}$ of the Dutch Copyright Act, indicated by the "Taverne" license above, 


\title{
High-definition micropatterning method for hard, stiff and brittle polymers
}

\author{
Yiping Zhao ${ }^{\mathrm{a}}$, Roman Truckenmuller ${ }^{\mathrm{b}, \mathrm{c}}$, Marloes Levers ${ }^{\mathrm{a}}$, Wei-Shu Hua ${ }^{\mathrm{a}}$, Jan de Boer ${ }^{\mathrm{a}, \mathrm{b}, \mathrm{c}}$, Bernke Papenburg a,* \\ a Materiomics B.V., Maastricht, The Netherlands \\ ${ }^{\mathrm{b}}$ Department of Tissue Regeneration, MIRA Institute for Biomedical Technology and Technical Medicine, University of Twente, Enschede, The Netherlands

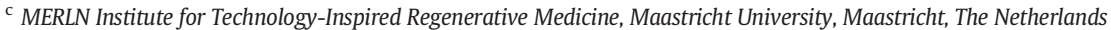

\section{A R T I C L E I N F O}

\section{Article history:}

Received 3 August 2016

Received in revised form 25 September 2016

Accepted 2 November 2016

Available online 5 November 2016

\section{Keywords:}

Micropatterning

Polystyrene

Polymers

Topography

Hot embossing

OrmoStamp

Molds

Microfabrication

\begin{abstract}
A B S T R A C T
Polystyrene (PS) is the most commonly used material in cell culture devices, such as Petri dishes, culture flasks and well plates. Micropatterning of cell culture substrates can significantly affect cell-material interactions leading to an increasing interest in the fabrication of topographically micro-structured PS surfaces. However, the high stiffness combined with brittleness of PS (elastic modulus 3-3.5 GPa) makes high-quality patterning into PS difficult when standard hard molds, e.g. silicon and nickel, are used as templates. A new and robust scheme for easy processing of large-area high-density micro-patterning into PS film is established using nanoimprinting lithography and standard hot embossing techniques. Including an extra step through an intermediate PDMS mold alone does not result in faithful replication of the large area, high-density micropattern into PS. Here, we developed an approach using an additional intermediate mold out of OrmoStamp, which allows for high-quality and large-area micro-patterning into PS. OrmoStamp was originally developed for UV nanoimprint applications; this work demonstrates for the first time that OrmoStamp is a highly adequate material for micro-patterning of PS through hot embossing. Our proposed processing method achieves high-quality replication of micropatterns in PS, incorporating features with high aspect ratio (4:1, height:width), high density, and over a large pattern area. The proposed scheme can easily be adapted for other large-area and high-density micropatterns of PS, as well as other stiff and brittle polymers.
\end{abstract}

(C) 2016 Elsevier B.V. All rights reserved.

\section{Introduction}

Micro- and nano-topographies substantially influence cell behavior [1-5], including cell morphology, differentiation and proliferation [6]. Currently, a number of micropatterning approaches are available, providing a powerful platform for promoting cell reaction in cell biology and tissue engineering. One of most widely applied micropatterning technique is microcontact printing technology, for modelling tissue microenvironment, originally developed by George Whitesides [7]. However, there are several challenges and key limitations associated with current microcontact printing technologies. For instance, pattern stability and reliability, conventially cannot switch substrate regions from non-adhesive to adhesive for sequential patterning. Usually this requires gold coating of substrate and low throughput. [8]. Major disadvantages are that elaborate patterns with features more complex than parallel stripes or pillars, high-density arrays with complex patterns, are difficult to fabricate [7,9-10]. Although powerful, conventional

\footnotetext{
* Corresponding author.

E-mail addresses: Wei-shu.hua@materiomics.com (W.-S. Hua), bernke.papenburg@materiomics.com (B. Papenburg).
}

microcontact printing technology does suffer from significant drawbacks. Methods for micropatterning surfaces have proliferated rapidly in the past decade [11], particularly in the production of micro-topographies into regular cell culture devices, which is in high demand. Studied topographies include a wide variety of geometries that can be applied to a range of different materials. Polystyrene (PS) is one of most widelyused materials in cell-based research due to its good biocompatibility, low cost, optical clarity and easy sterilization by gamma or electronbeam irradiation. Regular disposable cell culture dishes and well plates made from PS are readily and commercially available. Specialty cell culture products featuring e.g. compact microfluidics or micropatterning, however, are hardly available commercially.

Manufacturing reproducible and reliable specialty PS devices requires a fast, high-quality, low-cost and robust microfabrication method. Current methods for PS devices are limited to those developed for research applications, and use conventional techniques such as solvent casting, micro-injection molding, and hot embossing [12-19]. From these, hot embossing is the general approach to fabricate devices from thermoplastic materials for laboratory use and medium-volume manufacture purposes [19]. When looking at higher-volume production methods, direct hot embossing of PS using typical hard molds, e.g. made from silicon ( $\mathrm{Si}$ ) or nickel (Ni), is not feasible due to PS's high 
stiffness (elastic modulus 3-3.5 GPa) and brittleness (breaking strain around 3\%). Well-known issues arise, such as incomplete mold filling and high demolding forces, leading to mold and polymer device damage [20]. Thus, researchers have introduced template molds of epoxy glue or polydimethylsiloxane (PDMS) into the fabrication process, to facilitate easy processing and demolding [12-13,16,18-19,21-22]. PDMS is well-known for use in microfluidic systems [23-24] and soft lithography [25-28], and is mainly used due to its flexibility and accuracy in micropattern transfer performance. For example, Dusseiller and coworkers demonstrated successful fabrication of indent microwell arrays in PS film by hot embossing using PDMS molds.

For fabrication of large-area, high-density and high-definition surface topographies into PS devices, however, processing through epoxy glues or PDMS intermediates appear to be insufficient. When following a similar scheme as Dusseiller et al. [21], we encountered severe feature deformations when recreating our large-area, high-density and protrusive features in PS. Additionally, uniform pressure distribution and hence good replication over the full $100 \mathrm{~mm}$ silicon wafer surface appears challenging $[16,22]$. Therefore, we developed a new method to overcome the aforementioned issues by using a sequence of two intermediate molds: the first made of PDMS and the second made of OrmoStamp. OrmoStamp was selected for its high fidelity of pattern replication (resolution down to $50 \mathrm{~nm}$ ), mechanical stability (elastic modulus of $650 \mathrm{MPa}$ ), and thermal stability during hot embossing (stable up to $270^{\circ} \mathrm{C}$ ) [29]. OrmoStamp is a UV-curable hybrid-polymer, and is primarily developed as a tool for UV nanoimprint lithography (UVNIL) fabrication [30-32].

This new processing method is evaluated by replication of the challenging design of our TopoChip into PS. The TopoChip, which is created by a computational generated pattern, has an area of $20 \mathrm{~mm} \times 20 \mathrm{~mm}$. One TopoChip contains 4356 TopoUnits: each covering an area of $290 \mu \mathrm{m} \times 290 \mu \mathrm{m}$ and possessing its own unique topography. TopoUnits are separated by $10 \mu \mathrm{m}$ thick walls, and in total, are made up of $2176 \mathrm{dif}-$ ferent features. Topographies within each TopoUnit are generated with varying contours and have lateral dimensions ranging roughly from $3 \mu \mathrm{m}$ to $30 \mu \mathrm{m}$. In the silicon TopoChip master mold, the topographies are fabricated with a depth of $10 \mu \mathrm{m}$ by deep reactive ion etching (DRIE), and $10 \mu \mathrm{m}$ wide and $30 \mu \mathrm{m}$ deep trenches (walls in the PS device) are created in between the TopoUnits. A detailed description of the TopoChip design and fabrication can be found in [33].

In this paper, OrmoStamp is demonstrated for the first time as a functional material for PS hot embossing, aside from its primary application in UV-NIL. With the presented scheme, we enable a robust microfabrication method for high-quality, large-area and high-density topographical replication into hard, stiff and brittle polymers.

\section{Materials and fabrication methods}

\subsection{Process scheme}

Before starting the PS microfabrication process, the silicon TopoChip master mold is fabricated by silicon micromachining technologies [33]. The silicon TopoChip mold is first cleaned in Piranha solution $\left(\mathrm{H}_{2} \mathrm{SO}_{4}: \mathrm{H}_{2} \mathrm{O}_{2}=3: 1 \mathrm{v} / \mathrm{v}\right.$, at a temperature of about $\left.95^{\circ} \mathrm{C}\right)$ for $30 \mathrm{~min}$, rinsed with deionized (DI) water, spun dry with $\mathrm{N}_{2}$, and finally a monolayer of trichloro( $1 H, 1 H, 2 H, 2 H$-perfluorooctyl)silane (FOTS, Sigma-Aldrich) is deposited on the mold from gas phase under vacuum conditions in a desiccator. Afterwards, the fabrication of intermediate PDMS and OrmoStamp molds and PS hot embossing follows the scheme illustrated in Fig. 1. The complete process scheme consists of three subschemes: A. PDMS mold fabrication; B. OrmoStamp mold fabrication; C. PS device fabrication. To further clarify feature properties, the features in the silicon TopoChip mold and OrmoStamp mold are indentations while the features in the PDMS mold and the final PS devices are protrusions.

\subsection{PDMS mold fabrication}

PDMS handling and device fabrication techniques are well described and documented in literature [24,34]. Here we give a short description of the process, which is shown in Fig. 1, subscheme A. The curing agent and the base (Sylgard 184® silicone elastomer kit, Dow Corning Corporation) are well mixed (1:10, w/w) and degassed in a desiccator. $12 \mathrm{~mL}$ PDMS pre-polymer is cast on a full $100 \mathrm{~mm}$ silicon wafer to receive a 1-1.5 mm thick PDMS mold (Fig. 1, A2). Afterwards, it is cured on a leveled hot plate or oven at $80{ }^{\circ} \mathrm{C}$ for a minimum of $8 \mathrm{~h}$ (Fig. 1, A3). The PDMS film is peeled off from the silicon master mold (Fig. 1, A4) and can be readily used to fabricate the OrmoStamp mold.

\subsection{OrmoStamp mold fabrication}

The method to fabricate the OrmoStamp mold is depicted in Fig. 1, subscheme B. OrmoStamp is an UV curable inorganic-organic hybrid polymer and OrmoPrime ${ }^{\circledR} 08$ is an adhesion promoter for OrmoStamp. Detailed information about these two polymers can be found in the manufacturer's processing guidelines (Micro Resist Technology $\mathrm{GmbH}$ ) [29]. In our method, the fabrication process is the following:

(B1) Borofloat wafers (Borofloat ${ }^{\circledR} 33$ from Schott) of $100 \mathrm{~mm}$ diameter and $500 \mu \mathrm{m}$ thickness are used as a substrate. After Piranha cleaning (Piranha procedure as described in Section 2.1) and dehydration bake on a hot plate at $120^{\circ} \mathrm{C}$ for a minimum of $10 \mathrm{~min}$, OrmoPrime ${ }^{\circledR 08}$ is spin coated on the Borofloat wafer at $3000 \mathrm{rpm}$ for $30 \mathrm{~s}$ and then baked on a hot plate at $150{ }^{\circ} \mathrm{C}$ for $5 \mathrm{~min}$. In our experiment, the Borofloat wafer with the OrmoPrime ${ }^{\circledR 08}$ coating is prepared right before the application of OrmoStamp.

(B2) A droplet of $1 \mathrm{~mL}$ OrmoStamp is slowly dispensed on the PDMS mold (more detailed discussion in Section 3.2) and is slowly brought into contact with the primed Borofloat wafer. Slow spreading of the droplet between the Borofloat wafer and the PDMS mold avoids air bubbles getting trapped.

(B3) Filling of the gap between the two substrates completes by capillary force and takes about 15-30 min.

(B4) The OrmoStamp film between the PDMS mold and the Borofloat wafer stack is exposed to $350-450 \mathrm{~nm}$ UV light for $120 \mathrm{~s}$ with the light intensity set at $12 \mathrm{~W} / \mathrm{cm}^{2}$ (EVG $620 \mathrm{i}$-line exposure system).

(B5) The PDMS mold can easily be peeled off from the OrmoStamp mold, after which the latter immediately follows a hard bake at $130{ }^{\circ} \mathrm{C}$ on a hot plate (ramping up from $20{ }^{\circ} \mathrm{C}$ to $130{ }^{\circ} \mathrm{C}$ with a ramping speed of $5{ }^{\circ} \mathrm{C} / \mathrm{min}$ ). After hard baking for $30 \mathrm{~min}$ at $130^{\circ} \mathrm{C}$, the OrmoStamp mold is allowed to cool down together with the hot plate to room temperature.

The complete hard bake process takes about $3 \mathrm{~h}$.

To prepare the OrmoStamp mold for hot embossing (Section 2.4), first a gentle $\mathrm{O}_{2}$ plasma treatment is performed using reactive ion etching equipment (RIE, home-built) at $10{ }^{\circ} \mathrm{C}, 50 \mathrm{sccm} \mathrm{\textrm {O } _ { 2 }}$ flow, $75 \mathrm{mTorr}$ pressure, and $50 \mathrm{~W}$ CCP power for $30 \mathrm{~s}$. Then, a monolayer of FOTS is deposited from gas phase under vacuum conditions in a desiccator (Fig. 1, C1).

\subsection{Micropatterning of polystyrene}

Commercially available biaxially oriented PS films of $190 \mu \mathrm{m}$ (Goodfellow) are used in the hot embossing process, as depicted in Fig. 1, subscheme C, using the Obducat Eitre ${ }_{6} 6$ Nano Imprint Lithography system (Obducat, Sweden). The PS film and the OrmoStamp mold are brought into contact (Fig. 1, C2). Hot embossing for PS film is performed at a temperature of $140{ }^{\circ} \mathrm{C}$, and apply a pressure of $10 \mathrm{bar}$ for 


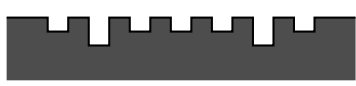

A1

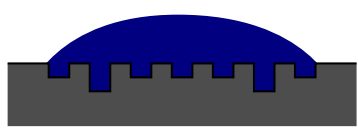

A2

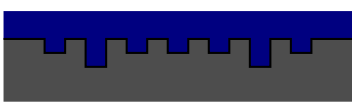

A3

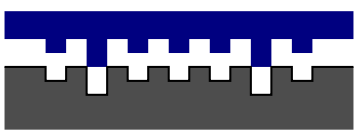

A4
B. OrmoStamp mold fabrication

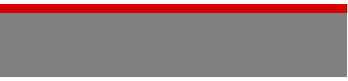

B1

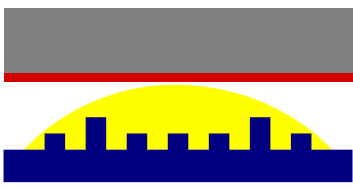

B2

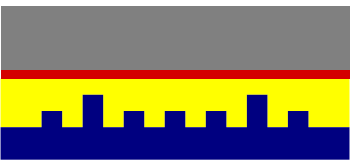

B3

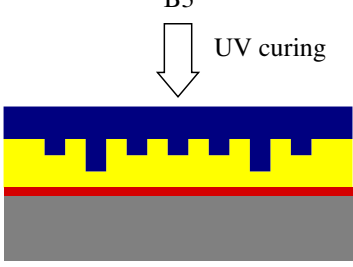

B4

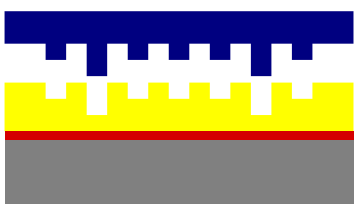

B5

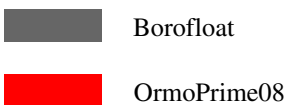

OrmoPrime08
C. PS device fabrication

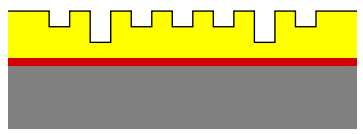

C1

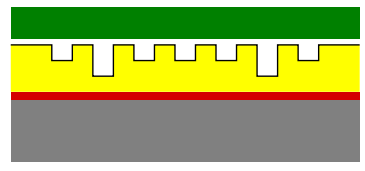

$\mathrm{C} 2$

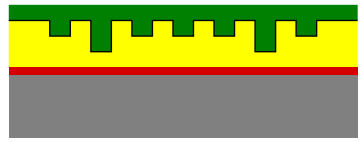

C3

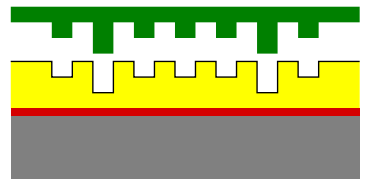

$\mathrm{C} 4$
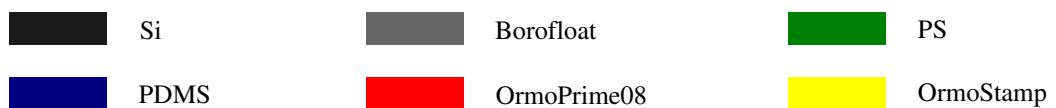

Fig. 1. Successful processing method for micropatterning stiff and brittle polystyrene. Sub-schemes presenting the various steps of the proposed fabrication method.

5 min (Fig. 1, C3). Finally, the PS film is separated from the OrmoStamp mold at $95^{\circ} \mathrm{C}$ (Fig. 1, C4).

\subsection{Cell culture}

A gentle $\mathrm{O}_{2}$ plasma treatment was first performed to the PS TopoChip using RIE at $10{ }^{\circ} \mathrm{C}, 50 \mathrm{sccm} \mathrm{O}_{2}$ flow, 75 mTorr pressure, and $50 \mathrm{~W}$ CCP power for $30 \mathrm{~s}$. After dicing, cleaning and sterilizing the PS TopoChips, the chips were immersed in culture medium at $37{ }^{\circ} \mathrm{C}$ in a controlled $5 \% \mathrm{CO}_{2}$ environment for a minimum of 3 days to ensure complete wetting of the surface. Subsequently, human mesenchymal stromal cells (hMSCs) were seeded onto the PS TopoChips using our custom designed seeding device to obtain optimal cell distribution over the TopoChips in combination with high seeding efficiency. The cells were cultured in $\alpha$-MEM (Invitrogen) supplemented with 10\% FBS (Lonza), 1\% pen/strep (Gibco), $0.2 \mathrm{mmol}$ AsAP (Sigma) and $3 \mathrm{mmol} \mathrm{L}$-Glutamine (Gibco). After 2 days of culture, the cells were fixed with 3.7\% formaldehyde (Sigma) and fluorescently labeled with Alexa Fluor ${ }^{\circledR} 488$ Phalloidin (Invitrogen) to stain the actin cytoskeleton and with Dapi (SigmaAldrich) to stain the nuclei. Imaging was performed with a BD Pathway 435 automated microscope.

\section{Results and discussion}

\subsection{Process development}

Several different fabrication processes were investigated to produce large area, high density functional micro-features on a PS device. First, the most straightforward approach to fabricate PS TopoChips is by directly imprinting the PS using a Si master mold. As expected, due to the rigidity of both silicon and PS, either one or both materials easily break when demolding the PS film from the Si mold. Additionally, known issues like incomplete mold filling occurred.

Next, we used a PDMS intermediate mold similar to the process by Dusseiller et al. where microwell arrays with diameters of $7 \mu \mathrm{m}$ to $70 \mu \mathrm{m}$ and $50 \mu \mathrm{m}$ spacing were fabricated in PS [21]. While they used a pattern design of low density and isolated protrusion features, we-in contrast-apply a design of high-density and interconnected indentation features over a large area. When using the intermediate PDMS mold to hot emboss the features into PS, part of the topographies were replicated. However, features were distorted, particularly in high density areas, and the wall features completely failed to form. It is hypothesized that the high thermal expansion coefficient of Sylgard 184 PDMS $\left(310 \mu \mathrm{m} / \mathrm{m}-{ }^{\circ} \mathrm{C}\right)$ [24] caused the expansion of the $290 \mu \mathrm{m} \times 290 \mu \mathrm{m}$ TopoUnits and, together with the applied 10 bar 


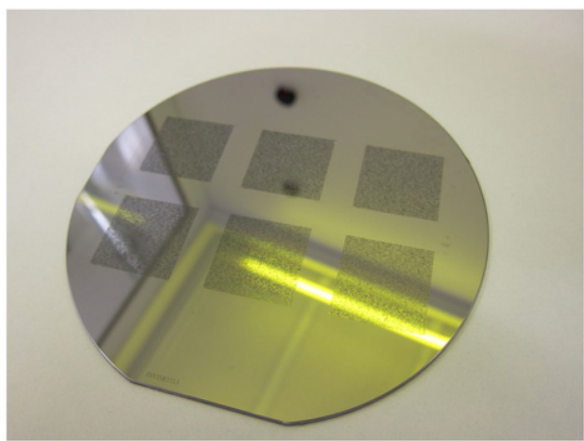

(a)

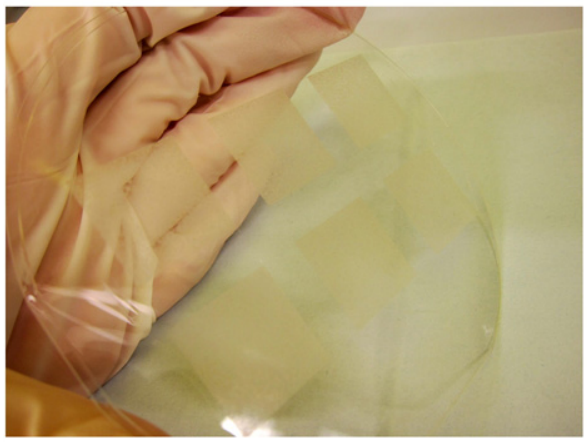

(c)

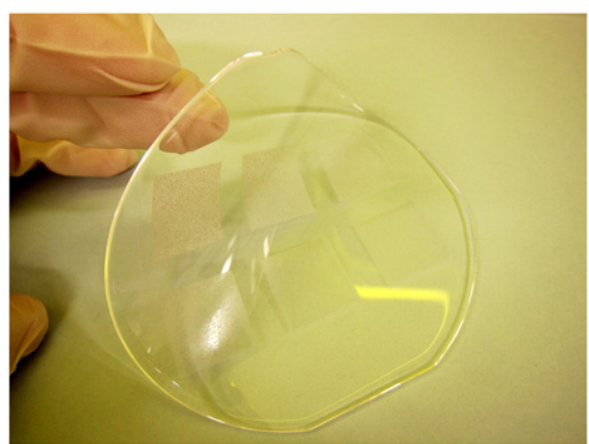

(b)

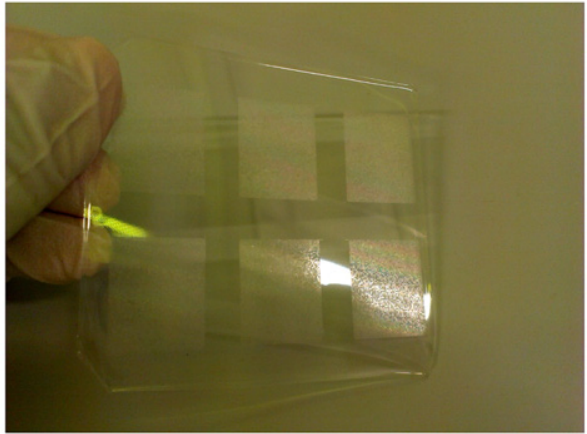

(d)

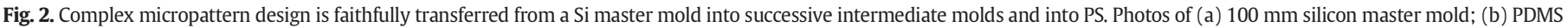
intermediate mold; (c) OrmoStamp intermediate mold; (d) PS TopoChips.

pressure, squeezed the $10 \mu \mathrm{m}$ channels closed. This would prevent PS from flowing into the cavities which form the walls. One approach to prevent the channels from closing would be lowering the process pressure as Dusseiller et al. demonstrated. However, this approach limits the approach to the replication of uncritical and low aspect ratio features, and would not be appropriate for our high-definition and high-aspect ratio (4:1, height:width) design. High pressure and critical procedure thus cannot be avoided.

The third attempted solution included fabrication of a composite mold made from PDMS combined with a Borofloat wafer to anchor the structures. The stiff composite mold should prevent the trenches from being blocked by the hypothesized PDMS expansion at high temperature and high pressure, similar to the composite PDMS mold fabrication method demonstrated by Duan et al. [34]. In our experiment, PDMS was spin-coated on the inverse Si master mold at a speed of $1500 \mathrm{rpm}$ for 30s. Then a Borofloat wafer was carefully placed on the spin-coated PDMS layer, avoiding air bubble formation. The mold fabrication was completed by curing the sandwiched PDMS-wafer stack on a leveled hot plate at $80{ }^{\circ} \mathrm{C}$ overnight. This fabrication method was not successful since the composite PDMS mold could not be separated from the inverse silicon master mold due to the rigid Borofloat wafer combined with the large contact area, high pattern density and large feature aspect ratio.

Subsequently, OrmoStamp was tested due to its reputation as a good molding material in hot embossing. OrmoStamp has an elastic modulus of $650 \mathrm{MPa}-$ in comparison, the elastic modulus of silicon is 130 $180 \mathrm{GPa}$; technical glass is $50-90 \mathrm{GPa}$; PDMS is $750 \mathrm{kPa}-$ and can be used in thermal hot embossing up to $270{ }^{\circ} \mathrm{C}$ [29]. The most straightforward method to fabricate the OrmoStamp mold was to cast OrmoStamp on the inverse Si master mold directly. However, we encountered great difficulties in avoiding air bubble inclusion while casting the OrmoStamp resin onto the inverse Si master mold, as well as separating the OrmoStamp mold from the Si mold afterwards due to tearing of the film.
To resolve the latter, a transparent substrate was applied for extra support while enabling good visibility to avoid bubble inclusion when dispensing the OrmoStamp. Borofloat wafers were initially used to function as support substrate; however, again the wafers were not separable due to their high rigidity, similar to the third aforementioned method where they were used as support for PDMS.

Finally, to solve the above issues, PDMS and OrmoStamp intermediate molds were combined and allowed for successful micropatterning of PS; the process is presented in Fig. 1. First, PDMS is cast onto the Si master mold to create an intermediate mold, followed by casting of OrmoStamp onto the PDMS intermediate mold to create the second intermediate mold, which is finally used to hot emboss a large area, high density and high quality micropattern design in PS. This procedure

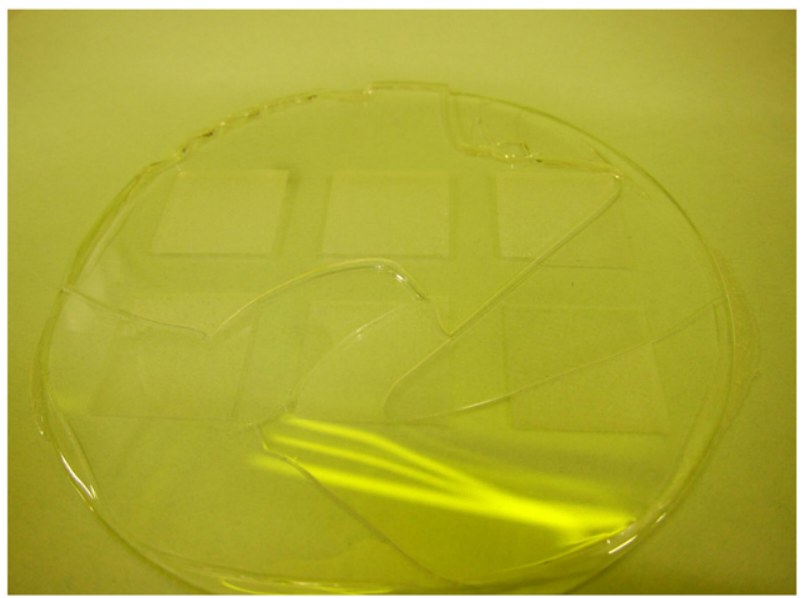

Fig. 3. A too thick OrmoStamp mold can lead to delamination from the support wafer. Photo of teared OrmoStamp intermediate mold due to delamination from the Borofloat wafer. 


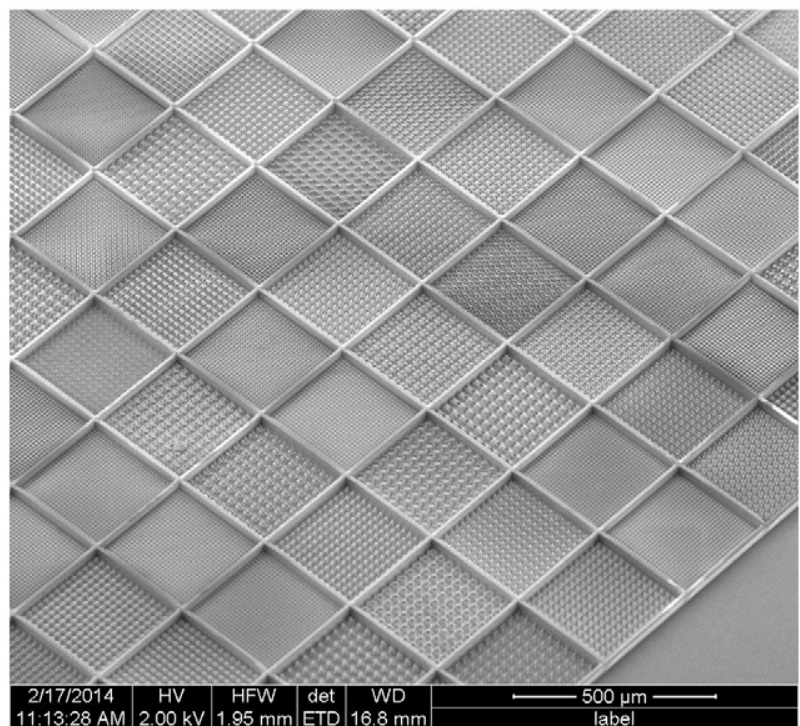

Fig. 4. High quality imprint of TopoUnits into PS is enabled by the proposed method. High magnification SEM image showing close-up selection of a PS TopoChip.

allows for accurate micro-feature replication, a relatively easy experimental handling process and long mold lifetime. Fig. 2 shows images of the silicon mold, the PDMS mold, the OrmoStamp mold and the micropatterned PS device.

\subsection{Details of PDMS and OrmoStamp intermediate mold fabrication}

To ensure proper quality of the intermediate molds, PDMS and OrmoStamp processing protocols had to be optimized. The most challenging part of handling PDMS is avoiding air bubble entrapment while dispensing the PDMS mixture onto the Si mold. Air bubbles will cause imperfect molding and lead to defective features. To avoid air bubbles, the PDMS mixture is degassed in a desiccator for at least $1 \mathrm{~h}$, followed by careful and slow introduction onto the Si mold during casting.

With respect to OrmoStamp, it is demonstrated in literature that the material can successfully be used for mold fabrication in UV-NIL applications [30-32]. Although handling issues were not specifically mentioned, we encountered two non-trivial issues during OrmoStamp handling. First, similar to casting PDMS, air is easily entrapped when applying Ormostamp. Placing the Borofloat wafer slowly and gently onto the Ormostamp droplet to smoothly contact the PDMS mold can prevent air bubble entrapment. Second, the adhesion of OrmoStamp to the Borofloat wafer is not optimal, which is dealt with by using OrmoPrime ${ }^{\circledR 08}$ to significantly increase the adhesion.

OrmoStamp has a high total volume shrinkage of $6 \%$ upon completion of the curing and hard bake process [29]. A thick OrmoStamp layer thickness, e.g. $>250 \mu \mathrm{m}$, can cause severe Borofloat wafer bending and can consequently lead to film detachment from the $500 \mu \mathrm{m}$ thick Borofloat substrate, as shown in Fig. 3. In this case, the lifetime of the OrmoStamp mold is greatly reduced due to the increased risk of delamination after 4 to 5 times of use. Minimizing the amount of OrmoStamp used reduces bending of the Borofloat wafer and greatly lengthens the lifetime of the OrmoStamp intermediate molds. Limiting the amount of OrmoStamp used allows for optimal molds thicknesses of only 150$200 \mu \mathrm{m}$ and can easily be used for about 20 times without any visible damage.

\subsection{Micropatterning PS}

PS is available with a range of different physical properties and chemical compositions, and has a $\mathrm{T}_{g}$ of approx. $100{ }^{\circ} \mathrm{C}$ that may vary slightly. To ensure the most optimal imprinting quality, a variety of hot embossing temperatures and pressure settings were tested for

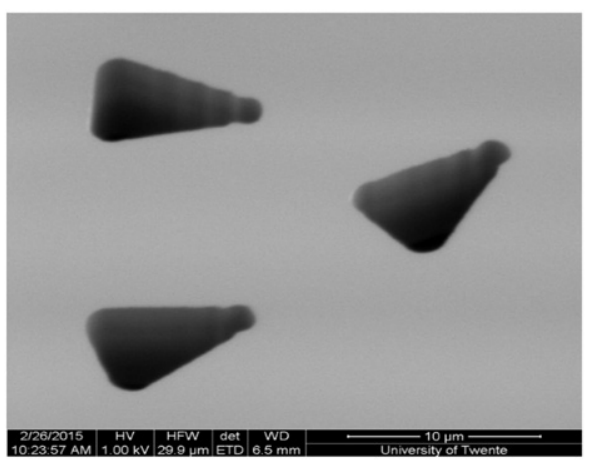

(a)

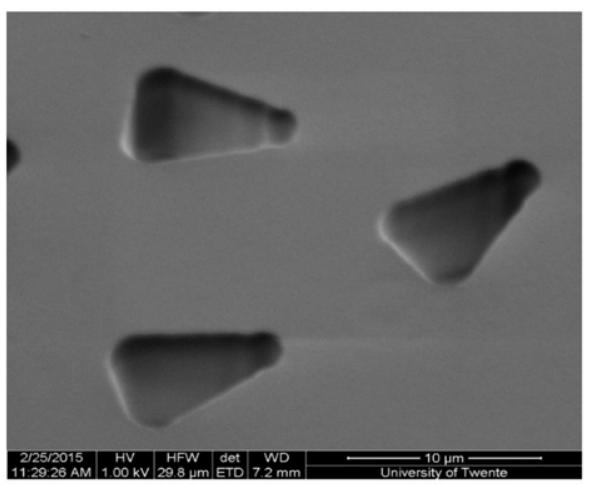

(c)

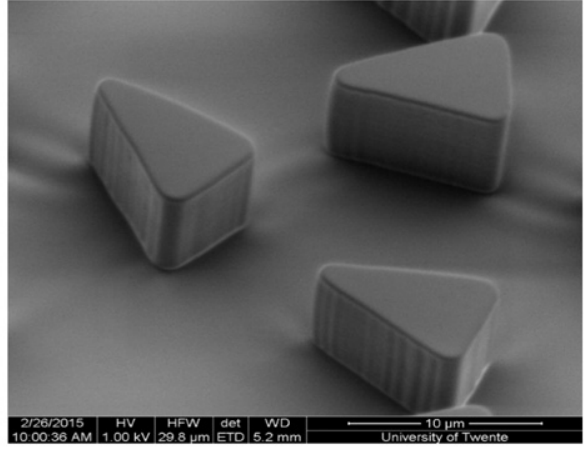

(b)

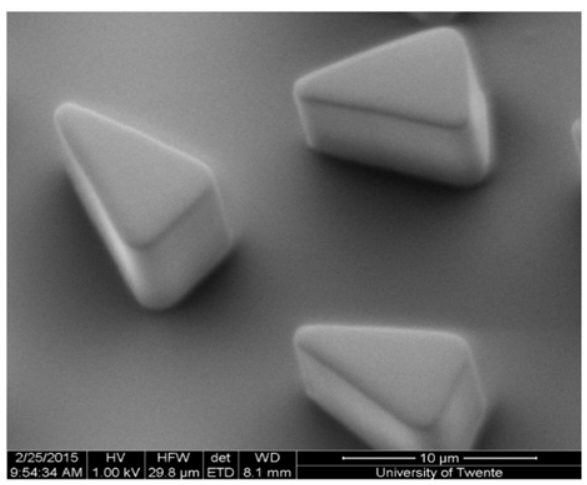

(d)

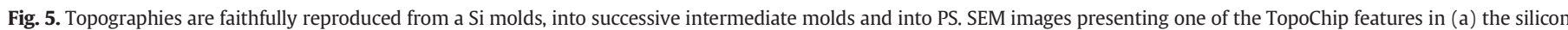
TopoChip master mold, (b) the PDMS intermediate mold; (c) the intermediate OrmoStamp mold; (d) PS. 


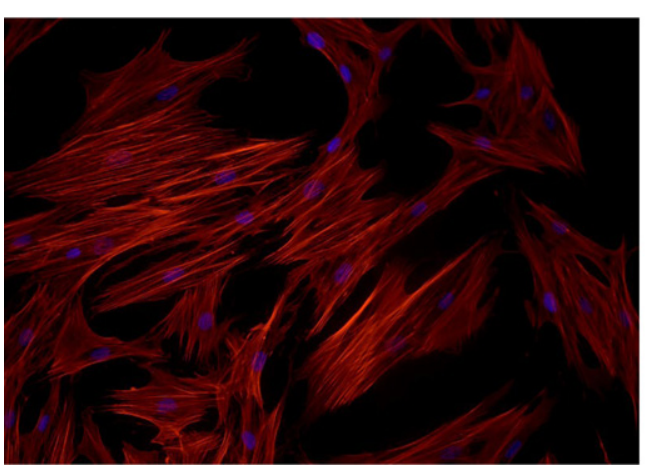

(a)

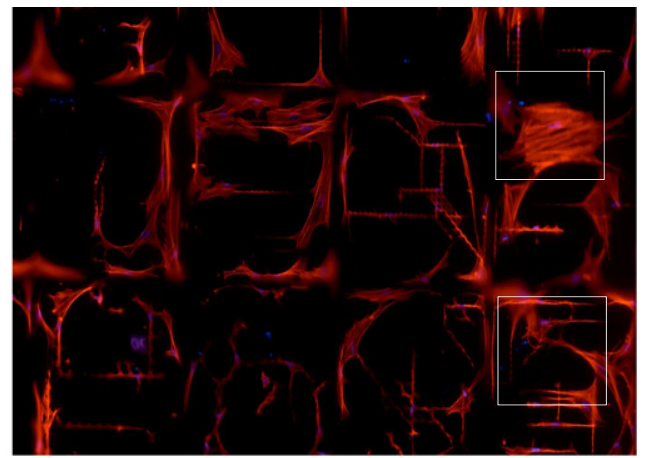

(b)

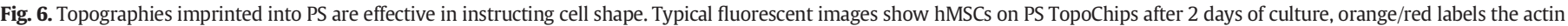
cytoskeleton of the cells and blue labels the nuclei, (a) hMSCs on a non-patterned part of the PS TopoChip, (b) hMSCs in a number of TopoUnits (walls are indicated by white lines).

two commercially available PS materials. The best replication results are obtained when applying a temperature of $140{ }^{\circ} \mathrm{C}$ and a pressure of 10 bar for 5 min; Fig. 4 presents a close-up image showing TopoUnits faithfully imprinted into PS.

SEM and optical microscopy are used to inspect the fidelity of feature replication from the Si master molds to the final PS device. Optical microscopy gives an overview of the quality of full film replication while SEM shows the details of the replicates. 4356 unique topographies are included in the TopoChip design. Fig. 5 presents the original design in the Si master mold and the final replication into PS of one topography, which consists of triangle contours and an aspect ratio of $4: 1$ (height:width).

Demolding of the PS film from the OrmoStamp intermediate mold has to be performed immediately after finishing the hot embossing process and upon reaching $95^{\circ} \mathrm{C}$. Waiting longer before demolding, i.e. reaching a lower working temperature like $60^{\circ} \mathrm{C}$, can lead to additional thermal shrinking and stiffening of the PS film, which can bend the OrmoStamp mold, and lead to delamination from the Borofloat wafer or even tearing of the OrmoStamp mold. Easy demolding of PS from the OrmoStamp mold at $95^{\circ} \mathrm{C}$ is most likely caused by the elastic modulus of OrmoStamp (650 MPa) enabling slight temporary deformations and thus good separation from the stiff PS film.

The resolution and application of the developed method are mainly limited by both the resolution of conventional UV photolithography (around $2 \mu \mathrm{m}$ ) and the resolution of PDMS molding (around $700 \mathrm{~nm}$ in our experience). Regarding feature aspect ratio, PDMS molding is the limiting step and, as a rule of thumb, features with an aspect ratio larger than 10:1 (height:width) are prone to collapse.

\subsection{Cell culture on micropatterned PS}

To prove that no disadvantageous side-effects originated from the proposed hot embossing scheme (i.e. using PDMS and OrmoStamp template molds and applying a FOTS coating to the OrmoStamp mold before using it in hot embossing of PS), a cell culture experiment was conducted. Fig. 6 shows fluorescent images, taken with a BD Pathway 435 automated microscope, of the hMSCs on the PS TopoChips. Fig. 6.a shows hMSCs on a non-patterned part of the PS TopoChip, whereas image Fig. 6.b shows hMSCs in a number of TopoUnits. These images demonstrate that the cells behave equally on the pre- and post-processed PS, indicating the proposed scheme brings no harmful side-effects to cells.

On the non-patterned surface (Fig. 6.a), the cells spread well. On the unique topographies featured in the individual TopoUnits (Fig. 6.b), the cells take up distinct cell shapes due to the directing influence topographies have on cell behavior; and thus, show the topographies are effective in instructing cell shape and behavior.

\section{Conclusions}

We demonstrated a robust fabrication scheme to imprint stiff and brittle polymers, like PS, using PDMS and OrmoStamp as intermediate molds. Even though PS is widely known and used as a bio-compatible material, relatively few microfabrication methods have been developed due to the material's stiffness and brittleness. The PDMS intermediate mold ensures successful transfer of the large area, high density, complex micropattern design from the original Si master mold, while the OrmoStamp intermediate mold brings high flexibility and accurate micropattern transfer to the final PS device. While OrmoStamp is primarily developed and implemented for UV-NIL applications, OrmoStamp is demonstrated here for the first time as a good mold material for micropatterning of hard and brittle polymers using hot embossing. High quality replication of micropatterns in PS, incorporating features with high aspect ratio (1:4, height:width) and high density over a large pattern area, is achieved. The proposed scheme can easily be adapted for other large-area and high-density micropatterns of PS, as well as other stiff and brittle polymers.

\section{Acknowledgement}

This work acknowledges the financial contribution of the Province of Limburg.

\section{References}

[1] A. Curtis, C. Wilkinson, Topographical control of cells, Biomaterials 18 (24) (1997) 1573-1583 (cited By (since 1996)827).

[2] R.G. Flemming, C.J. Murphy, G.A. Abrams, S.L. Goodman, P.F. Nealey, Effects of synthetic micro- and nano-structured surfaces on cell behavior, Biomaterials 20 (6) (1999) 573-588 (cited By (since 1996)816).

[3] V. Hasirci, H. Kenar, Novel surface patterning approaches for tissue engineering and their effect on cell behavior, Nanomedicine 1 (1) (2006) 73-90 (cited By (since 1996)26)

[4] E. Martinez, E. Engel, J.A. Planell, J. Samitier, Effects of artificial micro- and nanostructured surfaces on cell behaviour, Ann. Anat. 191 (1) (2009) 126-135 (cited By (since 1996)140).

[5] R. Truckenmller, S. Giselbrecht, M. Escalante-Marun, M. Groenendijk, B. Papenburg, N. Rivron, H. Unadkat, V. Saile, V. Subramaniam, A. Van Den Berg, C. Van Blitterswijk, M. Wessling, J. De Boer, D. Stamatialis, Fabrication of cell container arrays with overlaid surface topographies, Biomed. Microdevices 14 (1) (2012) 95-107 (cited By (since 1996)14).

[6] A. Reimer, A. Vasilevich, F. Hulshof, P. Viswanathan, C.A. van Blitterswijk, J. de Boer F.M. Watt, Scalable topographies to support proliferation and Oct4 expression by human induced pluripotent stem cells, Sci. Rep. 6 (18948) (2016).

[7] Y. Xia, G.M. Whitesides, Soft Lithography, Annu. Rev. Mater. Sci. 28 (1998) 153-184.

[8] E. D'Arcangelo, A.P. McGuigan, Micropatterning strategies to engineer controlled cell and tissue architecture in vitro, BioTechniques 58 (2015) 13-23.

[9] S.A. Ruiz, C.S. Chen, Microcontact printing: a tool to pattern. Advance article, Soft Matter 3 (2) (2007) 
[10] R.A. Desai, N.M. Rodriguez, C.S. Chen, Chapter 1 - "Stamp-off" to micropattern sparse, multicomponent features, Methods in Cell Biology, Micropatterning in Cell Biology Part A, 119, 2014, pp. 3-16.

[11] A. Atala, J.J. Yoo, Essentials of 3D Biofabrication and Translation, first ed., 2015.

[12] G. Mehta, J. Lee, W. Cha, Y.-C. Tung, J.J. Linderman, S. Takayama, Hard top soft bottom microfluidic devices for cell culture and chemical analysis, Anal. Chem. 81 (10) (2009) 3714-3722 (PMID: 19382754).

[13] E.W.K. Young, E. Berthier, D.J. Guckenberger, E. Sackmann, C. Lamers, I. Meyvantsson, A. Huttenlocher, D.J. Beebe, Rapid prototyping of arrayed microfluidic systems in polystyrene for cell-based assays, Anal. Chem. 83 (4) (2011) 1408-1417.

[14] W. Hu, E.K.F. Yim, R.M. Reano, K.W. Leong, S.W. Pang, Effects of nanoimprinted patterns in tissue-culture polystyrene on cell behavior, J. Vac. Sci. Technol. B 23 (6) (2005) 2984-2989.

[15] K.-S. Park, K.J. Cha, I.-B. Han, D.-A. Shin, D.-W. Cho, S.H. Lee, S.K. Dong, Mass-producible nano-featured polystyrene surfaces for regulating the differentiation of human adipose-derived stem cells, Macromol. Biosci. 12 (11) (2012) 1480-1489.

[16] A. Peter Russo, D. Apoga, N. Dowell, W. Shain, A.M.P. Turner, H.G. Craighead, H.C. Hoch, J.N. Turner, Microfabricated plastic devices from silicon using soft intermediates, Biomed. Microdevices 4 (4) (2002) 277-283.

[17] N.S.B.L. Carvalho, E.A. Schilling, G.J. Kellogg, Soft embossing of microfluidic devices, 7th International Conference on Miniaturized Chemical and Biochemical Analysis Systems, Squaw Valley, California USA, October 5-9, 2003.

[18] M. Heckele, W.K. Schomburg, Review on micro molding of thermoplastic polymers, J. Micromech. Microeng. 14 (3) (2004) R1.

[19] H. Becker, C. Gartner, Polymer microfabrication technologies for microfluidic systems, Anal. Bioanal. Chem. 390 (1) (2008) 89-111.

[20] N. Bogdanski, M. Wissen, S. Mllenbeck, H.-C. Scheer, Structure size dependent recovery of thin polystyrene layers in thermal imprint lithography, Microelectron. Eng. 84 (58) (2007) 860-863 (Proceedings of the 32nd International Conference on Microand Nano-Engineering).

[21] M.R. Dusseiller, D. Schlaepfer, M. Koch, R. Kroschewski, M. Textor, An inverted microcontact printing method on topographically structured polystyrene chips for arrayed micro-3-D culturing of single cells, Biomaterials 26 (29) (2005) 5917-5925 (cited By (since 1996)87).

[22] V.N. Goral, Y.-C. Hsieh, O.N. Petzold, R.A. Faris, P.K. Yuen, Hot embossing of plastic microfluidic devices using poly(dimethylsiloxane) molds, J. Micromech. Microeng. 21 (1) (2011) 017002.
[23] D.C. Duffy, J.C. McDonald, O.J.A. Schueller, G.M. Whitesides, Rapid prototyping of microfluidic systems in poly(dimethylsiloxane), Anal. Chem. 70 (23) (1998) 4974-4984.

[24] J.C. McDonald, G.M. Whitesides, Poly(dimethylsiloxane) as a material for fabricating microfluidic devices, Acc. Chem. Res. 35 (7) (2002) 491-499.

[25] B.D. Gates, Q. Xu, M. Stewart, D. Ryan, C.G. Willson, G.M. Whitesides, New approaches to nanofabrication: molding, printing, and other techniques, Chem. Rev. 105 (4) (2005) 1171-1196 (PMID: 15826012).

[26] J.-G. Lim, S.-S. Lee, K.-D. Lee, Polymeric arrayed waveguide grating using imprint method incorporating a flexible PDMS stamp, Opt. Commun. 272 (1) (2007) 97-101.

[27] A. Kumar, H.A. Biebuyck, G.M. Whitesides, Patterning self-assembled monolayers: applications in materials science, Langmuir 10 (5) (1994) 1498-1511.

[28] A. Perl, D.N. Reinhoudt, J. Huskens, Microcontact printing: limitations and achievements, Adv. Mater. 21 (22) (2009) 2257-2268.

[29] Micro Resist Technology, Processing guidelines - OrmoPrime ${ }^{\circledR} 08,2012$.

[30] A. Schleunitz, C. Spreu, T. Haatainen, A. Klukowska, H. Schift, Fabrication of mesas with micro- and nanopatterned surface relief used as working stamps for step and stamp imprint lithography, J. Vac. Sci. Technol. B 28 (6) (2010) (C6M37-C6M40).

[31] H. Schift, C. Spreu, M. Saidani, M. Bednarzik, J. Gobrecht, A. Klukowska, F. Reuther, G. Gruetzner, H.H. Solak, Transparent hybrid polymer stamp copies with sub-50-nm resolution for thermal and UV-nanoimprint lithography, J. Vac. Sci. Technol. B 27 (6) (2009) 2846-2849.

[32] H. Schulz, D. Lyebyedyev, H.-C. Scheer, K. Pfeiffer, G. Bleidiessel, G. Grtzner, J. Ahopelto, Master replication into thermosetting polymers for nanoimprinting, J. Vac. Sci. Technol. B 18 (6) (2000) 3582-3585.

[33] H.V. Unadkat, M. Hulsman, K. Cornelissen, B.J. Papenburg, R.K. Truckenmller, G.F. Post, M. Uetz, M.J.T. Reinders, D. Stamatialis, C.A. van Blitterswijk, J. de Boer, An algorithm-based topographical biomaterials library to instruct cell fate, Proc. Natl. Acad. Sci. (2011).

[34] X. Duan, Y. Zhao, A. Perl, E. Berenschot, D.N. Reinhoudt, J. Huskens, High-resolution contact printing with chemically patterned flat stamps fabricated by nanoimprint lithography, Adv. Mater. 21 (27) (2009) 2798-2802. 